\section{Desistência do crime}

Recebido: 14.09 .17

Aprovado: 07.03 .18

\section{Marcos Rolim*}

Resumo: O texto explora o conceito da desistência criminal, cada vez mais empregado na literatura criminológica contemporânea, a discutir o tema da estabilidade e da mudança comportamental a partir de novas bases teóricas. O trabalho discute as contribuições de diferentes teorias criminológicas e oferece uma síntese sobre as principais evidências encontradas em estudos longitudinais, destacando a relevância do fator etário para a desistência considerada na hipótese da "reforma de maturação". A partir da "perspectiva do curso de vida" (Sampson \& Laub, 1995), são indicados os chamados "pontos de virada" representados por eventos especiais correlacionados à desistência como o casamento, o nascimento do primeiro filho, a conquista de um emprego formal, entre outros. Com base na experiência internacional, sustenta-se que o fenômeno da desistência pode ser amplamente estimulado com políticas públicas e programas específicos, o que tenderia a produzir impactos positivos quanto à segurança pública. Em sua parte final, esse desafio é situado na realidade brasileira, com a sugestão de caminhos para a prevenção terciária, particularmente no que tange à integração comunitária dos egressos do sistema prisional.

Palavras chave: Desistência criminal. Reforma de maturação. Pontos de virada. Prevenção terciária. Apoio aos egressos.

\section{Desistance from crime}

Abstract: The text explores the concept of desistance from crime, which has been increasingly used in contemporary criminological literature, debating the subject of stability and behavioural change from new theoretical principles. The work discusses the contributions of different criminological theories and offers an overview on the main evidence found in longitudinal studies, highlighting the relevance of the age factor for the desistance considered by the "maturational reform" hypothesis. The "life-course perspective" (Sampson \& Laub, 1995) indicates the so-called "turning points", represented by special events correlated to desistance, such as marriage, birth of the first child, first formal job experience, amongst others. The international experience sustains that the phenomenon of desistance can be broadly stimulated through public policy and specific programs, which would most likely achieve positive results as to the overall safety of the population. In its final part, this challenge is applied to the Brazilian context, and paths to tertiary prevention, specifically regarding the community integration of former inmates, are suggested.

Key words: Desistance from crime. Maturational reform. Turning points. Tertiary prevention. Former inmate support.

\footnotetext{
* Marcos Rolim é doutor e mestre em sociologia pela Universidade Federal do Rio Grande do Sul (UFRGS). Presidente do Instituto Cidade Segura e membro do Conselho Administrativo do Centro Internacional para Promoção dos Direitos Humanos. Autor, entre outros, de $A$ síndrome da Rainha Vermelha, policiamento e segurança pública no século XXI (Zahar, 2006) e A formação de jovens violentos, estudo para a etiologia da violência extrema (Appris, 2016). <marcos@rolim.com. br>.
} 


\section{Introdução}

N o que diz respeito ao crime e à violência, as ciências sociais - particularmente a criminologia - têm procurado compreender o que poderia explicar o envolvimento com o ato disruptivo e quais as diferenças entre aqueles que se dedicam ao crime e os que observam as normas legais. Contemporaneamente, pouca importância tem sido dispensada pelos pesquisadores às diferenças entre aqueles que cometem crimes persistentemente ao longo de suas vidas e aqueles que se afastam das dinâmicas ilegais e se dispõem a um recomeço. O fenômeno, indicado na literatura com o conceito de "desistência", diz respeito à grande maioria dos casos de envolvimento de jovens com o crime e merece atenção especial.

Neste artigo, trataremos da desistência criminal como "um processo de abstenção do crime entre aqueles previamente engajados em um padrão criminal sustentável" (Maruna, 2001). A expressão "processo" dever ser destacada por lidarmos com dinâmica própria, em regra sem "ponto de corte" demarcado por decisão soberana em favor da desistência. Trabalhos como o de Farral e Calverley (2006) sustentam que pessoas dispostas a não mais reincidir em atividades criminais se envolvem, ainda, em algumas práticas ilícitas até que a decisão se viabilize. Haveria, assim, "falsas paradas" ou "recomeços", o que os autores designam com a expressão "recaídas" (relapses). As teorias mais recentes sobre a desistência sublinham que o processo envolve transformação cognitiva e mudança de identidade em que os indivíduos passam a se conceber como cidadãos comuns.

Maruna (2001) constatou que os desistentes costumam ter uma "narrativa pessoal de redenção" com elementos constantes. O primeiro deles é a noção do "eu verdadeiro", construção pela qual tudo aquilo que ocorreu antes e que vinculava o sujeito ao crime passam a ser vistos com dizendo respeito a um "outro eu", um eu distorcido que não era, essencialmente, o narrador. O segundo elemento é a identificação de "algo mau externo" responsável pelo comportamento condenável como, por exemplo, uma droga ilegal ou o álcool. O terceiro tema constante na narrativa tem a ver com a ação daqueles que acreditaram no sujeito e que o ajudaram de alguma forma. Essas pessoas, decisivas no "ponto de virada", são comumente descritas como aquelas que viram no narrador o seu "eu verdadeiro", percebendo, portanto, o seu valor. O quarto elemento é a ideia do sofrimento redentor. Ela aparece quando o sujeito afirma que aprendeu muito com a dor passada e que todo o processo o tornou mais forte, sem o que seria impossível chegar ao ponto em que chegou. Por fim, o quinto elemento é a projeção do narrador para o futuro, normalmente concebido como a dimensão em que ele irá realizar algo importante para melhorar a vida dos demais, promover o bem-estar ou refor- 
mar as instituições. Para Stone (2015), desistentes que elaboram uma história de redenção têm mais chances de resistir aos danos da estigmatização.

Tradicionalmente, as posições mais comuns diante do desafio da redução das taxas criminais e da violência estão representadas pelos caminhos da repressão e da prevenção ou, pelo menos, por ênfases distintas nos papéis a serem cumpridos, respectivamente, pelo direito penal e por políticas com foco em fatores de risco ${ }^{1}$. Esta dinâmica especial de polarização tem, entre outros resultados danosos, dificultado que se considere o tema da desistência criminal e que se reconheça sua importância como fenômeno social. Trata-se de circunstância grave que explica porque, a rigor, não possuímos políticas de prevenção terciária ${ }^{2}$ no Brasil e porque, para além dos textos legais e das promessas de ressocialização, poder público e sociedade se somam para tornar a vida dos desistentes um inferno.

Apresentaremos algumas das evidências significativas a respeito da desistência criminal, sintetizando as abordagens criminológicas a respeito do tema, com destaque para a "perspectiva de curso de vida" (life-course perspective) sustentada por Sampson e Laub (1995). Ao final, sugerimos caminhos a serem considerados pelos gestores em segurança pública no Brasil, para uma política pública mais eficiente quanto à prevenção, capaz de produzir resultados positivos em curto prazo.

\section{A extensão do fenômeno criminal}

Quando nos referimos ao fenômeno criminal, é comum imaginar que as condutas disruptivas sejam caracteristicamente aquelas experimentadas por um determinado grupo de pessoas. No linguajar comum e estereotipado, se assume que atos criminais são aqueles praticados por "bandidos". Os que são reconhecidos como cumpridores de seus deveres, as chamadas "pessoas de bem", não cometeriam crimes. A moldura é comum, mas diz respeito mais propriamente às histórias infantis, povoadas por vilões e super-heróis. No mundo real, as fronteiras entre a observação da lei e sua violação são muito menos marcadas. Em determinados momentos, ao longo das nossas vidas, pode-se mesmo afirmar que elas são bastante ambíguas.

Sabemos disso graças aos "estudos de autorrelato" (self-report studies) que permitem que entrevistados respondam a questionários sob total anonimato. Tal metodologia, que começou a ser empregada em meados do século passado, tem sido substancialmente desenvolvida, alcançando um patamar de sofisticação, validação e confiança notáveis (Thornberry \& Krohn, 2000) ${ }^{3}$. Tais trabalhos trouxeram à tona uma extensão do fenômeno criminal até então insuspeita. Em estudo clássico, Far-
1. No caso brasileiro, o contraponto às posições mais conservadoras não tem sido oferecido pela ideia de prevenção com foco em fatores de risco para o crime e a violência, mas pela noção genérica de "políticas sociais", o que fecha o círculo de simplificações e equívocos que vicia o debate sobre segurança pública no país.

2. Em criminologia, entende-se por "prevenção primária" o tipo de política de prevenção de caráter universal.

A prevenção secundária é aquela necessária para a abordagem de grupos de pessoas em situação de risco, tanto para o envolvimento com o crime quanto para a vitimização. Considera-se como prevenção terciária as iniciativas delineadas para sujeitos que se envolveram com o crime.

3. Passou-se, por exemplo, a medir mais adequadamente a frequência e a variedade de delitos cometidos. Para se evitar a interpretação errônea do próprio autor sobre a dimensão do ato ilegal praticado, os modernos estudos de autorrelato têm apresentado questões que se sucedem às respostas afirmativas para um conjunto de delitos envolvendo, 
por exemplo, uma avaliação sobre os valores dos bens subtraídos para os casos de furto ou roubo, a extensão dos danos causados às vítimas para os casos de agressão, e assim sucessivamente.

4. Lambert Adolphe Jacques Quetelet (1796-1874) foi um astrônomo, matemático, estatístico e sociólogo belga, fundador do Observatório de Bruxelas. rington (1989), por exemplo, encontrou 96\% de respostas afirmativas para "pelo menos um crime em minha vida", em amostra de pessoas de até 32 anos.

Sabe-se que o fenômeno criminal se concentra nos períodos da adolescência e dos primeiros anos de vida adulta. Como regra, os jovens se envolvem em atos delituosos de menor gravidade. Thornberry e Krohn (2000) concluíram que inexiste correlação estatisticamente significativa entre os relatos positivos para o crime feitos pelos jovens e sua origem social, revelando que adolescentes e jovens adultos de classe média tinham tantas probabilidades de se envolver em crimes quanto adolescentes e jovens adultos de famílias pobres. A conclusão é contraintuitiva e oferece um radical contraste com os registros criminais e com os perfis dos adolescentes e jovens adultos processados judicialmente; o que sugere que a distância entre os dados colhidos em pesquisas e o perfil social dos jovens condenados estaria revelando não um "retrato do crime", mas um retrato a respeito do trabalho dos órgãos de persecução, sobre seus filtros e prioridades.

\section{A reforma de maturação}

O primeiro estudo a constatar a concentração de atos delituosos na adolescência e nos primeiros anos de vida adulta foi desenvolvido por Quetelet ${ }^{4}$. Ao observar as taxas criminais na Inglaterra e na França entre 1826 e 1829, percebeu que havia uma "idade de pico" entre os jovens (Beirne, 1987). De lá para cá, os levantamentos disponíveis sugerem uma constante no fenômeno. Este ponto mais destacado nas faixas etárias no qual onde se concentrariam os delitos, estaria em torno dos 21 anos para os homens e 16 anos para as mulheres (Graham \& Bowling,1995). Por razões que importa analisar, a grande maioria destes jovens que cometem atos disruptivos deixa de se envolver em práticas do tipo, enquadrando seu comportamento nas expectativas sociais de respeito e observação às normas legais (Hirshi \& Gottfredson, 1983). Uma pequena parcela deles permanece cometendo crimes, afirmando esta conduta como um estilo de vida e constituindo o que identificamos como "carreiras criminais" (Piquero et alii, 2007).

A Figura 1 mostra a tendência de distribuição etária para os crimes violentos nos Estados Unidos, em 2013. As linhas permitem visualizar o "pico" etário, entre 19 e 24 anos, para aqueles que foram presos acusados da prática de homicídios dolosos, estupros, roubos, lesões corporais, outros tipos de agressões e porte ou posse ilegal de armas de fogo.

O trabalho de Sheldon e Eleanor Glueck, Unraveling juvenile delinquency (Desvendando a delinquência juvenil), publicado em 1950 - um dos mais amplos e 
FIGURA 1

TIPOS DE CRIMES VIOLENTOS E IDADE

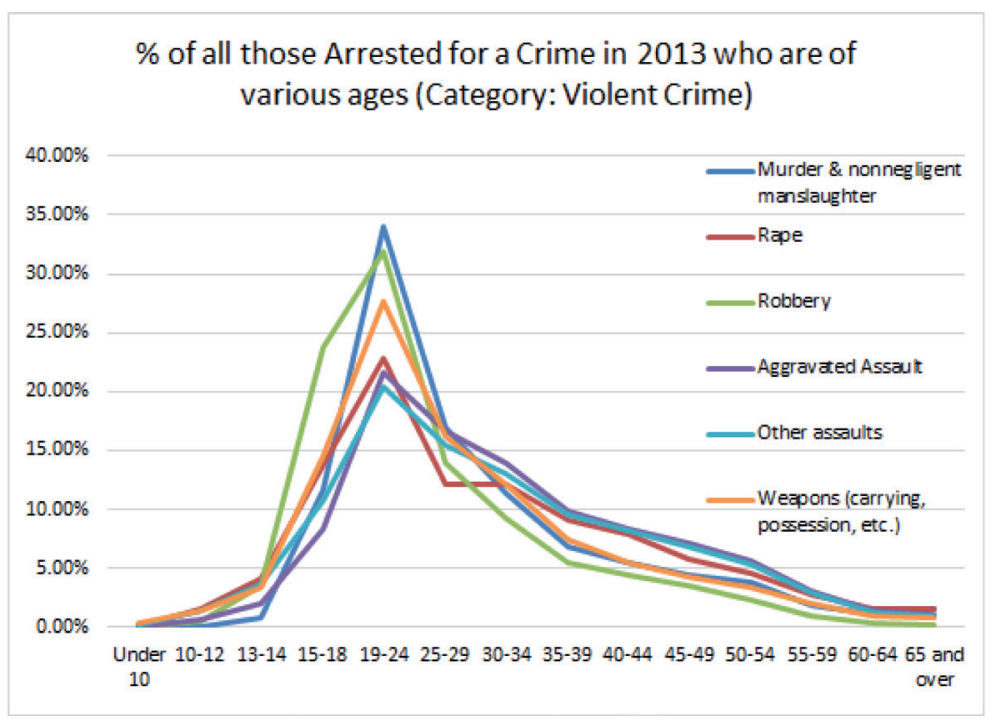

Fonte: US Department of Justice, Federal Bureau of Investigations (FBI), Uniform Crime Reports. Table 38: Arrests by age -2013 .

Disponível em: <http://wpsites.maine.edu/criminology/lecture-4-general-characteristics-of-crime-and-criminals/>.

ambiciosos estudos etiológicos sobre o crime já realizados -, havia tratado do tema da concentração dos atos infracionais entre adolescentes e jovens adultos e a posterior desistência com a chamada "hipótese da maturação". Para eles, duas dinâmicas estariam presentes: de um lado, o processo de aprendizagem e socialização que permite a introjeção de normas e valores morais; de outro, o processo orgânico de maturação cerebral. Por esta abordagem, a criminalidade tenderia a diminuir após os 25 anos de idade, independentemente de qualquer intervenção, sendo o envelhecimento o único fator significativo no processo reformador.

A intuição dos Gluecks é hoje amparada pelas evidências dos estudos mais recentes sobre o funcionamento cerebral. De fato, o cérebro passa por um processo de maturação, cujo estágio final está no lóbulo frontal onde se verificam mais mudanças durante a adolescência do que em qualquer outro período (Sowell et alii, 1999). Segundo os conhecimentos da neurociência, as funções executivas mais desenvolvidas do cérebro - como o planejamento, a memória verbal e o controle dos impulsos - estão situadas nos lobos frontais, exatamente as áreas que são as últimas do processo de maturação cerebral e que só estarão "prontas" por volta da metade da terceira década de vida, ou seja, entre os 20 e os 30 anos (Johnson et alii, 2009). 
5. Um dos aspectos não equacionados diz respeito aos critérios necessários para caracterizar a desistência criminal (registros policiais ou estudos de autorrelato, por exemplo) e o tempo considerado razoável para se concluir que alguém se afastou, de fato, do envolvimento com o crime.

6. Em razão deste resultado, a teoria da neutralização tem oferecido um importante ponto de apoio para a abordagem de superação de conflitos conhecida como "justiça restaurativa". O encontro com as vítimas, dentro de um modelo de justiça restaurativa, tornaria muito mais difícil manter construções ficcionais do tipo, permitindo com que os autores de atos delituosos enfrentem a realidade dos danos causados às pessoas

\section{Desistência, neutralização e autocontrole}

A desistência agrega dificuldades para a criminologia já que não constitui evento que possa ser observado - pelo menos não enquanto ocorrência criminal. Trata-se, antes, da ausência de eventos, do processo pelo qual alguém se afasta de certas práticas e decide construir outros caminhos, o que coloca desafios também para uma definição consensual ${ }^{5}$.

Sykes e Matza (1957) sustentaram que os jovens envolvidos com o crime seguem sendo influenciados pelos valores do respeito às leis, mas conseguem "desativá-los" - temporariamente -, como inaplicáveis ou desimportantes, usando técnicas de neutralização moral. Estas técnicas oferecem uma espécie de racionalização pela qual o ato desviante é integrado em uma moldura que o legitima por outros valores. Dessa forma, o autor do delito pode conviver com o fato de ter desrespeitado a norma, sem sentir-se culpado por isso e sem remorsos pelos danos produzidos às vítimas ${ }^{6}$.

A teoria de Sykes e Matza, inserida na tradição sociológica do interacionismo simbólico, recusa a noção segundo a qual haveria uma "subcultura delinquente" estruturada em torno de valores independentes da cultura dominante. As pessoas envolvidas em comportamentos delituosos compartilham valores tradicionais da sociedade e apreciam os objetivos de vida dos cidadãos cumpridores dos seus deveres. Elas intuiriam, entretanto, que seus pares desaprovam comportamentos em conformidade com as normas tradicionais - como a dedicação ao trabalho e ao estudo, por exemplo -, razão pela qual não expressariam os valores correspondentes.

Para Sykes e Matza, racionalizações do tipo estariam na origem do comportamento delituoso. Não seriam, enfim, apenas justificativas a posteriori. O problema aqui parece ser o não reconhecimento de que o comportamento humano nem sempre é racionalmente motivado. Aliás, uma visão de conjunto sobre a ação humana encontrará dificuldades em compreendê-la como consequência de escolhas racionais. Muitos são os estudos que demonstram a opção preferencial das pessoas por alternativas motivadas pelo preconceito ou por mecanismos que operam inconscientemente (Mlodinow, 2012; Ariely, 2010; Brafman \& Brafman, 2009). Justificativas racionais para a ação, por isso mesmo, costumam ser oferecidas post factum, o que, talvez, indique que hábitos e estruturas regulem mais frequentemente a ação do que a razão e que o inconsciente - como propõe a psicanálise -, seja uma espécie de "governo obscuro abaixo do trono polido da investidura do ego" (Hollis, 2010: 30). 
O tema da mudança de comportamento - tanto o fenômeno da desistência quanto o do envolvimento posterior com o crime - é muito importante também em termos de políticas públicas. Uma abordagem como a de Gottfredson e Hirschi (1990), por exemplo, construída a partir do argumento central de que as pessoas se afastam do crime à medida que consolidam mecanismos de autocontrole já na infância, atribuirá, por consequência, grande importância às relações entre pais e filhos. A explicação, todavia, pressupõe a estabilidade como consequência lógica (quem desenvolve autocontrole se afasta do crime, os que não desenvolvem tendem a se envolver com ele). O argumento, assim, não explica a mudança de comportamento, o que exige dados longitudinais, razão pela qual, aliás, Farrington (1986) e Blumestein et alii (1988) são críticos de Hirschi e Gottfredson. Por isso, Sampson e Laub (1995) consideram que não é possível explicar os padrões criminais na vida adulta apenas a partir da formação dos adolescentes e que a ausência de dados desde uma perspectiva histórica, longitudinal, inviabiliza a definição de políticas criminais eficientes.

\section{Perspectiva do curso de vida}

O estágio atual das pesquisas etiológicas sobre crime e violência não permite identificar com precisão as conexões entre as variáveis macroestruturais (classe social, etnia, mobilidade) e microestruturais (interação entre pais e filhos, disciplina) com o controle social informal. Isto exigiria uma nova teoria criminológica que, para Sampson e Laub, deve incorporar os seguintes elementos:

1. Família e escola são instâncias de mediação através das quais o contexto social modula comportamentos. Ambas as instituições são, por isso, fundamentais para se compreender a transgressão na infância e na adolescência.

2. Os comportamentos antissociais desenvolvidos precocemente na infância tendem a se manter na adolescência e na vida adulta em domínios variados.

3. Vínculos fortes no mundo adulto - como o casamento, nascimento dos filhos e emprego estável - explicam mudanças de conduta e o fenômeno mais amplo da desistência do crime.

Com estes pontos, teríamos uma teoria criminal com a perspectiva do curso de vida, capaz de dar conta não apenas da continuidade dos comportamentos disruptivos, mas também da mudança. As diferenças individuais - quanto ao autocontrole e 
7. Uggen (2000) sustenta que os resultados de sua pesquisa sugerem que os mecanismos mais eficazes de desistência entre adolescentes e jovens adultos devem ser de natureza distinta das oportunidades de emprego. Já uma modesta chance de trabalho alguns anos depois poderá fazer toda a diferença. Em estudo realizado com adolescentes em Santiago, no Chile, Mettifogo et alii (2015) encontraram que a família, os amigos e o trabalho foram os temas de maior relevância na narrativa dos jovens dispostos à desistência. quanto ao vínculo criado desde muito cedo entre as crianças e seus pais - seguem sendo importantes nesta perspectiva, mas há fatores supervenientes no mundo adulto que não podem ser subestimados.

Para além da teoria da reforma de maturação, temos a contribuição de Farrington (1992) sobre o controle social informal - ou "teoria do vínculo social" (social bond theory) -, que destaca a importância dos vínculos familiares, educacionais e de emprego entre os jovens adultos como variáveis que poderiam explicar melhor as mudanças de comportamento e, especialmente, a desistência criminal. Jovens com estes vínculos fragilizados manifestam pouca aderência às normas também porque teriam menos a perder. Matza (1964) foi um dos primeiros autores a enfatizar esses temas e o conjunto de evidências atualmente disponível parece afastar qualquer dúvida sobre sua importância. As correlações entre desistência criminal e emprego são muito fortes, tal como a escolaridade, o casamento e a paternidade/maternidade. Sampson e Laub (1995) concluíram que algumas instituições-chave para o controle social na transição para o mundo adulto - como emprego, serviço militar e casamento - são capazes de modificar caminhos. Vínculos sociais fortes podem explicar a desistência do crime entre adultos, apesar do histórico de persistente comportamento delituoso.

Sobre os vínculos propiciados por uma relação estável no mercado de trabalho, sabe-se que jovens entre 17 e 25 anos com empregos de baixa estabilidade apresentam quatro vezes mais chances de serem presos, oito vezes mais chances de terem comportamentos desviantes e seis vezes mais chances de abusar do consumo de bebidas alcoólicas do que jovens entre 25 e 32 anos, quando comparados com jovens da mesma idade que possuem empregos estáveis (Sampson \& Laub, 1995: 179). Empregos não são a resposta à criminalidade, o que se torna evidente se tivermos em conta as elevadas taxas de corrupção e de crimes praticados por altos executivos privados e por destacados membros do Estado em todo o mundo. Devem, entretanto, ser parte central de qualquer estratégia voltada à recuperação de pessoas com histórico criminal e cumprem um papel decisivo no processo de desistência, especialmente para os indivíduos com mais de 26 anos (Uggen, 2000) ${ }^{7}$.

Sobre a paternidade/maternidade, alguns estudos sustentam que ela contribui para a desistência criminal, porque permite um aumento do controle social informal (já que as expectativas de familiares e amigos se alteram), porque altera as atividades de rotina e permite uma mudança de identidade e de papeis sociais. Ter uma criança também implica, normalmente, o redirecionamento dos investimentos para a conformidade, "porque algo mais está em jogo". Para Maruna et alii (2003), a família e os laços mais íntimos de afeto podem oferecer às pessoas uma 
noção de sentido e uma direção até então inexistentes. Graham e Bowling (1995) encontraram, em amostra britânica, efeitos mais pronunciados de desistência nas mães quando comparados com os pais. Kreager et alii (2010 apud Monsbakken et alii, 2013) encontraram, em mães de um bairro pobre em Denver, no Colorado, Estados Unidos, que a maternidade - e não o casamento - era o primeiro "ponto de virada" (turning points) na trajetória delinquente das mulheres. Estudo de Monsbakken et alii (2013), na Noruega, com cruzamentos de dados sobre mais de 200 mil pessoas, homens e mulheres, que tiveram seu primeiro filho entre 1997 e 2001, sustenta que paternidade e maternidade podem ser definidores para a desistência criminal, mas apenas para homens e mulheres solteiros ${ }^{8}$. Shannon e Abrams (2007 apud Helyar-Cardwell, 2012) constataram que a experiência da paternidade produz um impacto positivo quanto à desistência. Sabe-se que presos que são pais e que mantêm laços fortes com seus familiares apresentam chances menores de reincidência (Niven \& Stewart, 2005 apud Helyar-Cardwell, 2012). LeBel et alii (2008 apud Helyar-Cardwell, 2012), em estudo com 130 presos por crimes patrimoniais, encontraram que aqueles que se identificavam como "pais de família" (familyman) tiveram taxas menores de reincidência em comparação com os que não se identificavam assim.

Para Carlsson (2012), não seriam os pontos de virada em si a causa da desistência criminal e sim a forma como estas mudanças operam. Determinada qualidade das relações estabelecidas no emprego, na relação conjugal ou nos programas educacionais faria toda a diferença, o que torna o tema ainda mais complexo. No mais, persistem dúvidas a respeito de se as correlações encontradas não seriam espúrias, vez que pessoas decididas a cometer crimes não procuram empregos, nem oportunidades educacionais ou casamentos (Gottfredson \& Hirschi, 1990). O que muitos estudos deixam evidente é que o processo de desistência criminal não é, como regra, decorrência exclusiva da agência individual, emergindo no espaço compreendido entre o indivíduo e a comunidade (Farral et alii, 2010; Vaughan, 2007; Maruna, 2001).

A maior parte das evidências a favor da estabilidade comportamental (criminal ou de conformidade com as normas) vem de estudos feitos por psicólogos e por cientistas sociais que pesquisam o comportamento antissocial genericamente. Nesses trabalhos, os conceitos legais de crime podem ou não estar presentes. Assim, por exemplo, Huesmann et alii (1984) constataram que a agressividade precoce em crianças é fator preditivo para agressividade e conduta criminal na idade adulta. Muitos outros estudos repetem o mesmo tipo de conclusão de modo que é possível se falar na formação de um consenso em torno da ideia de que crianças que apresentam altas taxas de comportamento antissocial possuem mais chances de
8. Eles constaram que, durante a gravidez, as ocorrências criminais com as mulheres caíam abruptamente em níveis próximos de zero, o que ocorreu igualmente nos três "recortes" de casais examinados: casados, coabitando e separados. A queda tão brusca implicava em retomada da curva criminal após o nascimento, mas em níveis mais baixos do que antes da gravidez. Na média, então, uma parcela das mães retornava às atividades delituosas, enquanto outra desistia dela, mas a desistência só foi significativa para as mães solteiras. No que se refere aos pais, também se verificou a queda na curva criminal anterior ao nascimento, mas sem os movimentos bruscos de caída e retomada. A desistência criminal em um prazo mais longo também foi significativa para os pais solteiros. Com relação aos pais casados ou que coabitavam, os dados sugerem que a desistência está associada a uma decisão anterior à gestação das esposas/ companheiras, possivelmente vinculada a um maior compromisso com elas. 
serem adultos com comportamento antissocial quando comparadas com as demais crianças (Loeber, 1982).

Os Gluecks também haviam identificado a estabilidade em Unraveling juvenile delinquency, sendo que a maioria dos jovens do grupo de controle (não envolvidos com práticas delituosas) permaneceu basicamente nos limites da legalidade, enquanto os demais seguiram envolvidos com o crime entre os 18 e os 25 anos. 0 que fez com que Robins (1978, apud Sampson \& Laub, 1995) tenha sumarizado os resultados dos estudos com quatro grupos de jovens do sexo masculino afirmando que o "comportamento antissocial adulto virtualmente requer comportamento antissocial na infância". Sampson \& Laub (1995) chamam a atenção, entretanto, para o seguinte paradoxo: apesar de os estudos revelarem que comportamento antissocial na infância é o melhor preditor para comportamentos antissociais na vida adulta, as crianças com comportamentos antissociais não se tornam, em sua maioria, adultos antissociais. Em verdade, olhar as carreiras criminais retrospectivamente faz com que se ressalte a estabilidade, mas, se olhamos prospectivamente as condutas de crianças disruptivas, veremos um cenário onde a mudança é muito mais saliente; o que é válido também para adolescentes envolvidos com o crime. Os autores entendem que baixo autocontrole é um dos elementos na configuração causal que pode conduzir alguém à prática do delito e que uma teoria criminal deve trabalhar tanto com a estabilidade quanto com a mudança das condutas. A teoria que eles sustentam enfatiza a importância dos vínculos sociais informais com a sociedade em todas as idades ao longo do curso da vida. Os efeitos do controle informal na infância, na adolescência e no mundo adulto são o centro do modelo teórico que eles apresentam.

\footnotetext{
Nós diferenciamos o curso de vida dos indivíduos na base da idade e argumentamos que as importantes instituições de controle formal e informal variam muito ao longo da vida das pessoas. Por exemplo: na infância e na adolescência, as instituições mais importantes de controle social são claramente a família, a escola, o grupo de amigos e as instâncias da justiça juvenil. Na fase de jovens adultos, as instituições de educação superior ou de treinamento vocacional, o trabalho e o casamento começam a ser salientes. O sistema de justiça juvenil é substituído pelo sistema de justiça para adultos. Finalmente, na metade da vida adulta, as instituições dominantes de controle social são o trabalho, o casamento, a paternidade, os investimentos na comunidade e o sistema de justiça criminal (Sampson \& Laub 1995: 17-18).
}

Parte-se aqui da teoria do controle social de Dürkheim: o crime e as práticas desviantes surgem quando os vínculos dos indivíduos com a sociedade são quebrados 
ou fragilizados. Mudanças que fortaleçam os vínculos do indivíduo com a sociedade diminuem o crime e a violência; inversamente, mudanças que enfraqueçam estes vínculos estimulam o crime. Os laços oferecidos pelos empregos e pela família são os inibidores-chave para o crime e o desvio entre adultos.

Os dados do estudo dos Gluecks mostram que os jovens envolvidos com a delinquência (registrada e reportada) apresentam uma tendência muito maior a não concluir os seus estudos; o mesmo é válido para as crianças de temperamento irritadiço e agressivo. Jovens envolvidos com delinquência apresentam pelo menos três chances mais de terem um histórico de instabilidade nos empregos quando chegarem à vida adulta; da mesma forma, comportamentos antissociais na infância estão relacionados à dependência econômica no mundo adulto. Jovens do sexo masculino envolvidos com delinquência, por fim, apresentam entre três e cinco vezes mais chances de se separarem ou de se divorciarem de suas parceiras.

O que não se pode esquecer é que as conexões entre o comportamento antissocial conhecido na infância e os resultados problemáticos na vida adulta podem ser explicadas, pelo menos em parte, pelas desvantagens estruturais e pela redução de oportunidades experimentadas por jovens institucionalizados e estigmatizados. 0 estigma de uma condenação pode mesmo estender-se para além de uma geração, explicando os efeitos da prisão dos pais sobre o comportamento delituoso dos fiIhos, independentemente das características familiares e de eventual precoce propensão ao crime (Hagan \& Palloni, 1990 apud Sampson \& Laub, 1995). Por isso, para alguns autores, a continuidade observada pelos estudos pode ser, em parte, ilusória (Farrington, 1986: 373). De outra parte, a estabilidade no emprego é bem mais difícil de ser alcançada por aqueles que vivenciaram a experiência juvenil ou adulta de encarceramento, o que reforça a importância do estigma como fator criminogênico.

\section{Política pública e desistência}

O fenômeno da desistência criminal precisa ser considerado no processo de delineamento de políticas criminais no Brasil. Observe-se, inicialmente, a idade de "pico" referida para as práticas criminais. O fato da idade referida situar-se, para os jovens do sexo masculino, nos primeiros anos da vida adulta parece já desnudar o mito de que a redução da idade penal possa produzir desencorajamento. Fosse assim, a tendência de queda nas práticas delituosas ocorreria quando da idade penal fixada e não alguns anos depois. A curva de crimes violentos em relação à idade mostrada na Figura 1 evidencia muito bem que aquelas práticas criminais aumentam nos Estados Unidos até os 24 anos. Assim, o fato de ser legalmente possível conduzir adolescentes acusados pela prática de delitos a cortes de adultos 
- e todo o rigor das penas introduzidas sob políticas criminais "duras" (tough on crime) - não produziu, nos Estados Unidos, qualquer sinal de redução nas práticas violentas até a "idade de maturação". O mesmo fenômeno se repete, com pequenas variações, em muitos outros países (Van Mastrigt \& Farrington, 2009).

Entre os adolescentes e jovens adultos já envolvidos com o crime no Brasil há disposições muito variadas. Alguns não concebem a possibilidade de um recomeço, porque imaginam que não saberiam fazer outra coisa ou porque pressentem que seriam incapazes de se afastar do crime sem serem mortos. Nestes casos, a chance de sobrevivência os vincula ao grupo criminal. Para além das dinâmicas violentas em que se envolveram, entretanto, parte expressiva destes jovens deseja sinceramente uma nova vida. Segundo Rolim (2016), o objetivo do recomeço está presente nos internos da Fundação de Atendimento Socioeducativo (Fase), do Rio Grande do Sul (antiga Fundação Estadual para o Bem Estar do Menor - Febem). Na amostra, os planos de recomeço apareceram fortemente vinculados às expectativas das companheiras e dos familiares. Os vínculos amorosos, no caso, parecem exigir uma mudança de atitude, mais do que um balanço racional a respeito do tipo de vida no mundo do crime. No centro do projeto, são nítidos os objetivos de "constituir família" e ter uma vida como as pessoas "normais", conforme pode se ver nos extratos a seguir.

Jovem 1 - Foi quando eu conheci minha mulher. Eu tava no crime, mas ela não. Ela é da Igreja. E aí nós nos conhecemo, aí eu comecei a me afastar um pouco e ficar mais com a família dela que era tudo gente de bem. Daí ela engravidou. Mas eu tava foragido e minha vida tava de cabeça prá baixo, uma coisa de louco. Daí ela pediu para que eu escolhesse entre ela e nosso filho ou o crime e a cadeia. Daí eu falei que escolhia ela e falei pro meu patrão o que tava acontecendo - "Ó, to saindo, não te devo nada, tu não me deve nada, tamo zerado." Aí eu saí do crime. Fui trabalhar com um amigo meu de padeiro. Até que a polícia me capturou dentro da padaria; aí eu to aqui.

Jovem 2 - Bah, na real eu tive muito desgosto que eu não queria ter passado. Sofri bastante, não adquiri nada. A coisa mais valiosa é a liberdade e, quando eu sair daqui, vou apreciar a liberdade. Não digo que eu vou conseguir um serviço de cara, eu vou me matricular e vou arrumar algum serviço. Eu sei que posso ganhar dinheiro com venda, sem roubar de ninguém. Posso guardar algum dinheiro, minha mãe quer ajudar, me dar uma moto, para trabalhar de moto. Se tiver no meu pensamento essa vontade de mudança, vou conseguir [...]. Quando eu caí preso eu passei a dar valor para minha família, porque meus amigos lá fora não teve um para se preocupar comigo, só a família da gente. Então, isso é 
um sentimento que eu aprendi. No caso, mesmo um matador tem sentimento. Na real eu só dei desgosto para minha família [...]. Foi na Febem que eu comecei a prestar atenção na religião e comecei a ler a Bíblia. No começo eu não entendia nada, mas aí tinha um obreiro da Igreja que me explicava a palavra de Deus. Foi quando eu comecei a ficar sereno. Por isso eu quero assumir meu filho quando sair daqui.

Jovem 3 - Sim, eu tenho uma namorada que vem me ver e ela conversa muito comigo e quer que eu mude. Ela fez 19 anos recém e falou que não quer ter filho comigo e tudo se for para seguir me visitando em cadeia. Que ela me visita aqui e teve que se humilhar prá isso, porque o pai dela não queria que ela me visse, mas a guria gosta de mim e veio igual e a intenção dela é que eu mude. Minha mãe também. Tem serviço no interior prá mim, no comércio e entrega de pizza, todo o ano. Agora vai da minha vontade, mas aqui eu não posso ficar. Não posso voltar lá prá vila caso que aí eles me matam. Só em outra cidade pra eu recomeçar (Rolim: 199-201).

Outro tema a ser enfrentado no Brasil com urgência diz respeito às dinâmicas criminógenas que acompanham encarceramento em massa, o que tem sido reforçado pela superlotação que promove o alojamento coletivo em galerias de detentos separados não pela gravidade de seus crimes, mas pelo pertencimento a facções criminais. Por esse caminho, o Estado se transformou em um dos mais eficientes organizadores do crime e as possibilidades da desistência criminal são desestimuladas. Notadamente, a experiência de privação de liberdade no Brasil não diz respeito à alfabetização, ao estudo ou à formação profissionalizante. Sobre essa condenação extrajudicial, se sobrepõe uma segunda dinâmica de natureza excludente: o estigma social sobre os egressos do sistema penitenciário. Ao contrário do que imagina o senso comum, muitos são os egressos que, uma vez em liberdade, buscam insistentemente o trabalho. São os que resistiram ao processo de organização criminal ou que desistiram dele. A grande maioria dos empregadores, entretanto, ao saberem que o pretendente possui antecedentes (não necessariamente condenação criminal), recusará qualquer oportunidade de emprego. Pesquisa realizada no Paraná por Wauters (2003) encontrou que, para 70\% dos egressos do sistema prisional, o preconceito é o principal motivo de não conseguirem trabalho. Assim, a pena já cumprida se revela perpétua e os egressos são como que empurrados em direção a estratégias ilegais de sobrevivência. Por conta do preconceito disseminado, a corrente criminógena se robustece e a violência é retroalimentada.

O processo de exclusão social produzido pelo estigma contra os egressos ainda não foi suficientemente estudado no Brasil. Não há, no mais, preocupação significativa com o tema no âmbito do poder público. Falamos, entretanto, de um dos proces- 
sos mais destacados da criminogênese moderna que poderia ser estancado com políticas de apoio aos egressos e de estreitamento das possibilidades estigmatizadoras. Observe-se, a propósito, a solução encontrada pela Holanda quanto às informações sobre antecedentes e condenações judiciais (Boone, 2011). Naquele país, quando alguém se inscreve para uma vaga no mercado, os empregadores podem solicitar a um serviço governamental se há óbice para que aquela pessoa seja contratada. O serviço não informará se o pretendente tem antecedentes, nem mencionará eventuais processos. Entretanto, se ele tiver sido condenado por maus tratos a uma criança, por exemplo, e desejar um emprego onde lidará diretamente com crianças, o serviço informará que, para aquela função, há óbice. Essa não seria a informação caso a vaga fosse de outra natureza. Assim, a legislação holandesa encontrou uma forma simples de preservar, ao mesmo tempo, os direitos da sociedade e do egresso.

O Brasil se ressente de políticas de prevenção efetivas e, a rigor, desconsidera as iniciativas exequíveis de prevenção terciária. Esta lacuna ocupa um espaço ainda mais proeminente entre nós, considerando-se a produção em escala industrial de egressos do sistema prisional e a radicalidade dos preconceitos que eles enfrentam.

Políticas efetivas de segurança pública podem e devem estimular a desistência criminal valendo-se, articuladamente, da estrutura do Estado e da sociedade civil. Com base na experiência internacional, sabemos que programas direcionados à reinserção de egressos podem cumprir papel destacado na desistência (Farrall, 2002 apud Maruna, 2010). No Brasil, são raros os estudos sobre reincidência e o tema da desistência não tem sido objeto de análise. Trabalho de Julião (2010) no Rio de Janeiro, entretanto, encontrou que o estudo no cárcere reduz as possibilidades de reincidência em $39 \%$, enquanto a experiência de trabalho prisional diminui as chances de novo envolvimento com o crime em 48\%. Os dados são expressivos, ainda mais se considerarmos a ausência de uma política nacional de trabalho e educação prisional e as condições precaríssimas com que contam os poucos projetos na área. Estudo de Cordeiro et alii (2014) identificou na qualidade da relação familiar, na autoestima, na aceitação social e nas oportunidades de emprego os fatores que mais impactam positivamente para a ressocialização de ex-detentos do Complexo Penitenciário de São Pedro de Alcântara (Cope), em Santa Catarina. O estudo realçou também as possibilidades virtuosas do trabalho prisional, assinalando o quanto a experiência tem surpreendido positivamente a Intelbras, empresa que montou uma unidade produtiva no complexo. Segundo seus gestores, os presos são mais produtivos que os funcionários regulares da empresa e desenvolvem técnicas inovadoras que aumentam e eficiência dos processos laborais. 
As pesquisas com desistentes têm mostrado que o processo costuma ser fortemente impactado por alguém ou por algumas pessoas que acreditaram na possibilidade deste resultado (Rex, 1999 apud Maruna, 2010). O trabalho de assistência social tende a ser especialmente importante nesses programas pela necessidade de auxílio prático nos momentos mais difíceis. Para além das responsabilidades públicas, os estudos revelam que as comunidades podem construir possibilidades virtuosas, produzindo mais desistentes na exata medida em que dão mostras de uma disposição de acolhimento. Para tanto, programas comunitários de integração de egressos, com a participação de voluntários, grupos religiosos, ativistas sociais e empreendedores deveriam ser estimulados (Lebel et alii, 2008 apud Maruna, 2010). Pesquisa de Fox (2015), que avaliou o impacto do programa comunitário de integração de egressos identificado pela sigla CoSA (Circles of Support and Accountability) ${ }^{9}$, no estado de Vermont, Estados Unidos, demonstrou que a integração comunitária pode ser precursora de um processo exitoso de desistência, ao invés de um resultado da desistência. Primeiro, porque o acolhimento dos egressos em uma comunidade serve para modelar a perspectiva de uma vida normal; segundo, porque as reuniões e o envolvimento comunitário permitem que as normas sejam compartilhadas e, por fim, porque a integração promove a desrotulação, prevenindo desvios secundários. Para a autora, trata-se de reconhecer, desde um ponto de vista ético e também pragmático, que uma sociedade capaz de punir deve ser também capaz de encerrar a punição.

As dinâmicas de etiquetamento, em contraposição, se reproduzem sistemicamente e são agenciadas, de início, por muitos policiais, agentes penitenciários e outros funcionários públicos vinculados ao sistema de justiça criminal, um fenômeno que é particularmente sensível no Brasil. Para tais agentes, a ocorrência do crime conforma o espaço onde se deslocam os "vagabundos". Os autores seriam, assim, um tipo especial de pessoas (ou quase-pessoas), uma gente que não valeria qualquer esforço e para quem, aliás, a simples consideração aparece como um deboche. Nesta moldura ideológica, a natureza dos autores faria com que seu comportamento fosse imutável. Noções do tipo, que se reproduzem como subcultura entre os agentes encarregados de cumprir a lei, trabalham concretamente como "profecias que se autocumprem"10, estreitando ainda mais as possibilidades da desistência criminal.
9. O programa foi concebido e aplicado originalmente no Canadá a partir de uma abordagem que se vale dos princípios da justiça restaurativa e que conta com a colaboração de voluntários que auxiliam os egressos considerados de alto risco e os integram à comunidade com sucesso.

10. A expressão selffulfilling prophecies foi proposta, em 1949, por Robert K Merton, em Social theory and social structure. 


\section{Referências}

ARIELY, Dan. Positivamente irracional: os benefícios inesperados de desafiar a lógica em todos os aspectos de nossas vidas. Rio de Janeiro: Campus Elsevier, 2010.

BEIRNE, Piers. Adolphe Quetelet and the origins of positivist criminology. American Journal of Sociology, v. 92, n. 5, p. 1140-1169, 1987.

BLUMENSTEIN, Alfred; COHEN, Jacqueline, FARRINGTON, David P. Criminal career research: its value for criminology. Criminology, v. 26, p. 1-35, 1988.

BOONE, Miranda. Judicial rehabilitation in the Netherlands: balancing between safety and privacy. European Journal of Probation, v. 3, n. 1, p. 63-78, University of Bucharest, 2011.

BRAFMAN, Ori; BRAFMAN, Rom. A força do absurdo. Rio de Janeiro: Objetiva, 2009.

CARLSSON, Christoffer. Using "turning points" to understand processes of change in offending. Notes from a swedish study on life courses and crime. British Journal of Criminology, v. 52, p. 1-16, 2012.

CORDEIRO, Laurentino André; COELHO, Kellen da Silva; KANITZ, Amarildo F.; SILVA GONÇALVES, Helen. Os reflexos da capacitação fora das grades: a ressocialização dos ex-detentos do complexo penitenciário de São Pedro de Alcântara (SC/Brasil) Reice. Revista Iberoamericana sobre Calidad, Eficacia y Cambio en Educación, v. 12, n. 2, p. 139-162, 2014.

FARRALL, S.; CALVERLEY, A. Understanding desistance from crime: Theoretical directions in resettlement and rehabilitation. Maidenhead (UK): Open University Press, 2006.

FARRAL, S., BOTTOMS, A.; SHAPLAND, J. Social structures and desistance from crime. European Journal of Criminology, v. 7, p. 546-569, 2010.

FARRINGTON, D. P. Explaining the beginning, progress, and ending of antisocial behaviour from Birth to adulthood. In: MCCORD, J. (Ed.). Facts, frameworks, and forecasts: advances in criminological theory. v. 3. New Brunswick (NJ): Transaction Publishers, 1992.

- Self-reported and official offending from adolescence to adulthood, In: KLEIN, M. W. (Ed.). Cross-national research in self-reported crime and delinquency. Dordrecht (NL): Kluwer, 1989. 
Age and crime. In: TONRY, Michael; MORRIS, Norval (Eds). Crime and justice. v. 7, p. 189-250. Chicago (IL): University Press, 1986.

FOX, Katheryn J. Theorizing community integration as desistance-promotion. Criminal Justice and Behavior, v. 42, n. 1, p. 82-94, 2015.

GOTTFREDSON, Michael; HIRSCHI, Travis. A general theory of crime. Stanford (CA): Stanford University Press, 1990.

GRAHAM, J.; BOWLING, B. Young people and crime. London: Home Office, 1995.

HELYAR-CARDWELL, Vicki. Fathers for good? Exploring the impact of becoming a father on young offenders' desistance from crime. Safer Communities, v. 11. n. 4, p. 169-178, 2012.

HIRSHI, Travis; GOTTFREDSON, Michael. Age and the explanation of crime. American Journal of Sociology, v. 89, p. 552-584, 1983.

HOLLIS, James, A sombra interior: porque pessoas boas fazem coisas ruins? São Paulo: Novo Século, 2010.

HUESMANN, L. R.; ERON, L. D.; LEFKOWITZ, M. M.; WALDER L. O. The stability of aggression over time and generations. Developmental Psychology, v. 20, p. 11201134, 1984.

JOHNSON, S. B. et alii. Adolescent maturity and the brain: the promise and pitfalls of neuroscience. Research in adolescent health policy. Journal of Adolescent Health, v. 45, n. 3, p. 216-221, 2009.

JULIÃO, Elionaldo Fernandes. O impacto da educação e do trabalho como programas de reinserção social na política de execução penal do Rio de Janeiro. Rev. Bras. Educ. v. 15, n. 45, 2010.

LOEBER, Rolf. The stability of antisocial child behavior: a review. Child Development, v. 53, p. 1431-1446, 1982.

MARUNA, Shadd. Making good: how ex-convicts reform and rebuild their lives. Washington (DC): APA Books, 2001.

MARUNA, Shadd; LEBEL, T. P.; LANIER, C. Understading desistance from crime. London: Rehabilitation Services Group; National Offender Managment Service; Ministry of Justice (UK), 2010. 
- Generativity behind bars: some "redemptive truth" about prison society. In: ST. AUBIN, E. de; MCADAMS, D.; KIM T. (Eds.). The generative society: caring for future generations, p. 131-151. Washington (DC): American Psychological Association, 2003.

MATZA, D. Delinquency and drift. New York: John Wiley and Sons, 1964.

METTIFOGO, Decio; ARÉVOlO, Camila; GOMÉS, Francisca; MONTEDÓNICO, Sofia; SILVA, Luis. Factores transicionales y narrativas de cambio en jóvenes infractores de ley: análisis de las narrativas de jóvenes condenados por la Ley de Responsabilidad Penal Adolescente. Psicoperspectivas, v. 14, n. 1, Valparaíso (CL), 2015.

MLODINOW, Leonard. Subliminar: como o inconsciente influencia nossas vidas. Rio de Janeiro: Zahar, 2012.

MONSBAKKEN, Christian Weisæth; LYNGSTAD, Torkild Hovde; SKARDHAMAR, Torbjørn. Crime and the transition to parenthood: the role of sex and relationship context. British Journal of Criminology, v. 53, p. 129-148, 2012.

PIQUERO, A. R.; FARRINGTON, D. P.; BLUMSTEIN, A. Key issues in criminal career research. New analyses of the Cambridge Study in delinquent development. Cambridge (MA): Cambridge University Press, 2007.

ROLIM, Marcos. A formação de jovens violentos: estudo sobre a etiologia da violência extrema. Curitiba (PR): Appris, 2016.

SAMPSON, Robert J.; LAUB, John H. Crime in the making: pathways and turning points through life. Cambridge (MA): Harvard University Press, 1995.

SOWELL, Elizabeth et alii. In vivo evidence for post-adolescent brain maturation in frontal and striatal regions. Nature Neuroscience, v. 10, 1999.

STONE, Rebecca. Desistance and identity repair: redemption narrative as resistance to stigma. British Journal of Criminology, v. 56, n. 5, p. 956-975, 2015.

SYKES, G. M.; MATZA, D. Techniques of neutralization: a theory of delinquency. American Sociological Review, v. 22, n. 1, p. 664-670, 1957.

THORNBERRY, Terence P.; KROHN, Marvin D. The self-report method for measuring delinquency and crime. In: Measurement and analysis of crime and justice. Washington (DC): U.S. Department of Justice Office of Justice Programs Washington (DC), 2000. 
UGGEN, Christopher. Work as a turning point in the life course of criminals: a duration model of age, employment, and recidivism. American Sociological Review, v. 65, n. 4, p. 529-546, 2000.

VAN MASTRIGT, S. B.; FARRINGTON, D. P. Co-offending, age, gender and crime type: implications for criminal justice policy. British Journal of Criminology, v. 49, p. 552573, 2009.

VAUGHAN, Barry, The internal narrative of desistance. British Journal of Criminology, v. 47, p. 390-404, 2007.

WAUTERS, E. A reinserção social pelo trabalho. Curitiba: Universidade Federal do Paraná, 2003. 
